\title{
POLITITIKK
}

\section{Pro-atlantisk påvirkningspolitikk i Norge i årene rundt 1949}

\author{
Helge Danielsen \\ Institutt for forsvarsstudier, Forsvarets høgskole
}

\begin{abstract}
Sammendrag
Befolkningens oppslutning om norsk NATO-medlemskap har vært høy siden slutten av 1960-årene. I tiden rundt NATOs opprettelse, og de første ti-tolv årene deretter, viste imidlertid flere opinionsundersøkelser at rundt halvparten av de spurte tenderte $i$ retning av et ønske om norsk alliansefrihet $-i$ alle fall ideelt sett. Denne artikkelen viser hvordan representanter for allierte land og for NATOs egen informasjonstjeneste, i nært samarbeid med ulike norske aktører, arbeidet for å påvirke norske holdninger i årene rundt 1949. Målet for dette påvirkningsarbeidet var dels å øke oppmerksomheten og kunnskapen om alliansesamarbeidet, men også å sikre oppslutning om norsk vestorientering.
\end{abstract}

Nøkkelord: offentlig diplomati • opinionspåvirkning • nøytralisme $\cdot$ NATO

\section{Innledning}

I årene frem mot den atlantiske alliansens 70-årsjubileum, har det vært bred politisk og folkelig oppslutning om Nato-medlemskapets betydning for norsk sikkerhet. Alle norske regjeringer, uansett farge, har omtalt alliansen som et grunnfeste i norsk sikkerhetspolitikk. Årlige opinionsundersøkelser i regi av organisasjonen Folk og Forsvar har dessuten vist at en svært høy andel av de spurte mener at norsk Natomedlemskap er med på «... å trygge landet mot en fremmed makt» (Opinion, 2018). De siste tre årene har rundt $75 \%$ gitt uttrykk for dette synet (76\% i 2018), og fra slutten av 1960-årene har minst $60 \%$ delt denne vurderingen, med unntak for noen få år der oppslutningen har vært noen prosentpoeng lavere (ibid.; Alstad, 1993, s. 82;

\footnotetext{
^Kontaktinformasjon: Helge Danielsen, e-post: hdanielsen@ifs.mil.no

(C)2019 Helge Danielsen. This is an Open Access article distributed under the terms of the Creative Commons Attribution 4.0 International License (http://creativecommons.org/licenses/by/4.0/), allowing third parties to copy and redistribute the material in any medium or format and to remix, transform, and build upon the material for any purpose, even commercially, provided the original work is properly cited and states its license.

Citation: Helge Danielsen (2019). Pro-atlantisk påvirkningspolitikk $i$ Norge $i$ årene rundt 1949. Internasjonal Politikk, 77(1): 108-116. http://dx.doi.org/10.23865/intpol.v77.1620
} 
Tamnes, 1997, s. 62). Brutt ned på partipolitiske preferanser viser 2018-målingen at andelen som mener at NATO-medlemskapet trygger Norges sikkerhet er på mellom 75 og $90 \%$ i de største partiene, at 58\% av SV-velgerne i undersøkelsen deler denne oppfatningen, og at det kun er blant dem som sympatiserer med Rødt at andelen er under 50\% (nemlig 42\%). Andelen som er enig i at Norge bør bidra med soldater i NATO-operasjoner er også høy, her er 35\% helt enige og en like stor andel delvis enige, riktignok gitt forutsetningen at disse operasjonene skjer med mandat fra FN.

Disse tallene står delvis i kontrast til holdninger og oppfatninger i årene rundt opprettelsen av den atlantiske alliansen. I en undersøkelse gjennomført få måneder etter at Norge signerte Atlanterhavspakten svarte riktignok $54 \%$ av de spurte at tilslutningen til denne hadde økt Norges sikkerhet (Alstad, 1993, s. 82). I Stortingsvalget høsten 1949 gikk det regjerende Arbeiderpartiet frem, både i andel av stemmene og i antall mandater. Norges Kommunistiske Parti mistet halvparten av sin andel av stemmene sammenliknet med 1945, fikk en oppslutning på 5, 9\%, men mistet likevel alle sine mandater. Man skal være tilbakeholden med å tolke dette valget som en dom først og fremst over partienes utenriks- og sikkerhetspolitiske orientering, men det er likevel grunnlag for å si at Arbeiderpartiet ikke ble straffet av velgerne for sine veivalg. Undersøkelser fra årene like før og etter 1949 viste imidlertid ved flere anledninger at mindre enn halvparten av de spurte delte et positivt syn på norsk NATO-medlemskap. Amerikanske opinionsundersøkelser i Norge fra siste halvdel av 1950-årene viste dessuten at støtten til norsk vestorientering, som stort sett lå på mellom 45 og $48 \%$, i enkelte målinger var så lav som 30\%. I disse målingene kom det ikke frem noe ønske om å velge side med østblokken, maks $1 \%$ ønsket dette. Ønsket om $i k k e$ å velge side stod derimot sterkt, og var et foretrukket alternativ hos i underkant av $40 \%$ i de fleste målingene, men i enkeltmålinger (f.eks. i juni 1960) ga så mange som 60\% uttrykk for en slik nøytralistisk holdning (Bones, 2007, s. 170). Tilhengerne av norsk vestorientering og alliansemedlemskap kunne dermed ikke ta for gitt at den folkelige støtten til en slik politikk var vunnet en gang for alle, hverken i 1949 eller i 1960.

Målet med denne artikkelen er å vise hvordan pro-atlantiske krefter forholdt seg til norske holdninger til alliansen i årene rundt 1949, hvordan de forsøkte å påvirke dem, og hva som var formålet med denne påvirkningspolitikken. De viktigste aktørene i denne korte analysen er representanter for de største allierte, USA og Storbritannia, for NATOs egen informasjonstjeneste, og norske personer, miljøer og organisasjoner som samarbeidet med disse. Tidsrommet som behandles er i all hovedsak de to-tre årene før og etter 1949. Disse forsøkene på å påvirke offentlig opinion hang nært sammen med politiske og diplomatiske fremstøt for å påvirke norske myndigheter. Både det offentlige diplomatiet, og det tradisjonelle, politiske, gjenspeilte også avsendernes strategiske og politiske mål i den tidlige kalde krigen: Dels å sikre norsk vestorientering, og folkelig oppslutning om denne, dels å demme opp for Sovjetisk makt og innflytelse - politisk, militært og ideologisk. Den aktiviteten som beskrives her kan dermed knyttes til de delene av Atlanterhavspakten som beskriver et politisk verdifellesskap, og ikke minst til traktatens artikkel 2, som understreker 
viktigheten både av å styrke medlemslandenes politiske institusjoner, og av å skape en bedre forståelse for prinsippene som ligger til grunn for disse. Norsk vestorientering startet imidlertid ikke med beslutningen om å slutte seg til Atlanterhavspakten. Det gjorde heller ikke det pro-atlantiske påvirkningsarbeidet.

\section{Innsalget av Marshallplanen}

Da det amerikanske hjelpeprogrammet kjent som Marshallplanen (som offisielt bar navnet European Recovery Programme - ERP) ble lansert sommeren 1947, var entusiasmen internt i den norske regjeringen begrenset. Spørsmålet om deltakelse i dette programmet var en utfordring mot den såkalte «brobyggingspolitikken» som Norge hadde ført siden 1944. Ambisionen var å unngå å bidra til blokkdannelse eller splittelse i Europa (eller mellom stormaktene), bl.a. basert på et håp om at FN skulle fylle en reell rolle som garantist for internasjonal sikkerhet. I praksis gikk politikken i stor grad ut på å holde hodet lavt, og å unngå en stillingtaken som ville plassere Norge i den ene eller andre leiren. Spørsmålet om deltakelse i ERP var til å begynne med utfordrende, fordi dette i praksis ville være å velge side med vesten. Slik saken utviklet seg ble dilemmaet snudd på hodet, i og med at det å $i k k e$ delta ville kunne tolkes som å avvise vestlig samarbeid. Sovjetunionen takket nei til tilbudet om Marshallhjelp, og la føringer på andre østeuropeiske land om å giøre det samme. Vesteuropeiske land, inkludert det nøytrale Sverige, takket ja til deltakelse. Grunnlaget for brobyggingspolitikken forsvant gradvis i løpet av høsten 1947, og etter kuppet i Tsjekkoslovakia i slutten av februar 1948 og sovjetisk press mot Finland rundt samme tid, ble den endelig oppgitt til fordel for en tydelig vestorientering.

Regjeringen og Arbeiderpartiledelsens dilemma skyldtes ikke utelukkende affinitet til den blokkuavhengige linjen, men hadde også sammenheng med at et linjeskift ville rokke ved en bred innenrikspolitisk konsensus. Innad i Arbeiderpartiet var det splittelse i disse spørsmålene, og skepsis til nært samarbeid med USA fantes ikke bare til venstre, men også hos enkelte på borgerlig side. Selv om Arbeiderpartiledelsen følte seg trygg på at en svært stor del av partiet ville slutte opp om en eventuell vestorientering, regnet den også med at så mange som $1 / 4$ av medlemmene, inkludert viktige tillitsvalgte, ville være enten skeptiske eller direkte motstandere. De fleste større norske avisene var også først avventende til ERP, men med unntak av Friheten og andre kommunistiske aviser var de raskere til å innta en positiv holdning enn f.eks. regjeringen. I opinionen for øvrig var det relativt positive holdninger til USA i mer allmenn forstand, samtidig som andelen av befolkningen som var kritiske til landets utenrikspolitiske ambisjoner var relativt høy i europeisk kontekst. Skepsisen til Sovjetunionen var imidlertid betydelig mer utbredt (Pharo, 1976; Bones, 2007, s. 162-3; Liland, 1992; Sverdrup, 1996; Danielsen \& Pharo, 2009).

Marshallhjelpen var, i tillegg til et gjenoppbyggingsprogram, også ment som et tillitsskapende tiltak fra amerikansk side overfor potensielle allierte i Europa. Både 
overfor politikere og opinion var dette ett av flere virkemidler for å signalisere at USA ikke hadde tenkt å overlate europeerne til seg selv, hverken når det gjaldt økonomisk utvikling eller med tanke på det som i økende grad ble oppfattet som en politisk og militær trussel fra Sovjetunionen. Amerikanerne lot imidlertid ikke den økonomiske bistanden tale for seg, denne ble tvert imot kombinert med en omfattende propaganda- og informasjonsoffensiv. Måten amerikanske myndigheter gikk frem på for å promotere Marshallhjelpen ble langt på vei mønsterdannende for seinere påvirkningsarbeid. Som i andre land hadde den lokale Marshallplanadministrasjonen (Economic Cooperation Administration, ECA) i Norge sin egen informasjonstjeneste. Denne sørget bl.a. for å forsyne aviser og andre medier med stoff om ERP, både faktaopplysninger om forsendelser og om samarbeidets gang, men også ideologisk pregete fremstillinger av bakgrunnen for og målene med programmet. Organiserte studiereiser til USA for ulike eksperter og representanter for næringer som ville nyte godt av Marshallhjelpen, var i seg selv et bidrag til påvirkningsarbeidet. I tillegg ble både omtale av selve reisene, og intervjuer med deltakerne, solgt inn som mulige historier til pressen. Seinere, etter at ERP hadde blitt avløst av Mutual Defence Assistance Program (MDAP, der såkalt «våpenhjelp» erstattet generell bistand), ble liknende dekning av norske militære som hadde utdanningsopphold i USA brukt på samme måte. Det ble også arrangert studiereiser for journalister og andre, til USA eller til NATO-baser og hovedkvarter i Europa (Ellwood, 2012; Danielsen, 2017).

Film var et svært viktig medium i arbeidet med å spre kunnskap om og bearbeide publikums holdninger til Marshallhjelpen. Et stort antall filmer ble produsert og distribuert for å formidle innholdet i og ambisjonene for hjelpeprogrammet, for å presentere de ulike deltakerlandene for hverandre, og ikke minst: for å innprente budskapet om at økonomiske og politiske utfordringer best lot seg løse gjennom internasjonalt samarbeid. I overkant av 300 filmer ble distribuert i Norge, både via kommunale kinoer og ulike lag og foreninger over hele landet. En av de viktigste brukerne var Arbeidernes Opplysningsforbund. Enkelte organisasjoner hyret inn folk til å reise rundt i sine distrikter for å vise film også på små steder. Filmer som viste hvordan ERP bidro til gjenoppbygging av norske næringer ble laget med tanke på visning i grunnskolen. De ansvarlige for denne delen av det amerikanske informasjonsarbeidet konkluderte selv med at filmene nådde ut til absolutt alle lag av den norske befolkningen, og over hele landet. Enkelte måneder kunne det totale antallet mennesker i Norge som så en Marshallplanfilm, eller en annen amerikansk propagandafilm, komme opp i ca. 80 000. I tillegg til film ble det arrangert utstillinger med samme formål, den største var trolig utstillingen «Norske varer giennom Marshall-hjelpen", som fant sted ved Steen \& Strøm i Oslo i november 1950, der tretti norske produsenter av forbruksvarer viste frem hvordan produksjonen hadde kommet på fote takket være ERP. Nærmere 150000 personer besøkte utstillingen, og pressedekningen var omfattende (Danielsen \& Pharo 2009; Fritsche, 2018). 


\section{Antikommunistisk agitasjon}

I tillegg til forsøkene på å selge inn Marshallplanen og annet transatlantisk samarbeid som noe positivt, var påvirknings-, informasjons- og propagandaarbeidet til de vestlige stormaktene, både i Norge og i Europa ellers, i dette tidsrommet sterkt dominert av antikommunisme. Dels var det et mål å fremstille kommunismen og Sovjetunionen $\mathrm{i}$ et så negativt lys som mulig - for å svekke eventuell sympati i de vesteuropeiske landene. Dels arbeidet USA, Storbritannia og etter hvert NATOs egen informasjonstjeneste (NATO Information Service (NATIS), etablert i 1950), med å produsere og distribuere mot-propaganda for å møte kampanjer i regi av Sovjetunionen og dens allierte. Formålet med NATIS var, i utgangspunktet, å bidra til økt kunnskap og oppslutning om NATO i medlemslandene, i samarbeid med de ulike landenes informasjonstjenester. Av ulike grunner nådde ikke NATIS fullt ut disse målene i løpet av alliansens første leveår. Tjenesten ble ikke prioritert økonomisk, og hadde dermed begrensete budsjetter. Ulike medlemsland hadde ulike ønsker når det gjaldt koordinering og samarbeid på dette området - amerikanerne ønsket en høy grad av samarbeid, mens f.eks. britene ville begrense det. En av grunnene til britenes holdning var ønsket om å unngå at andre land fikk innsyn i virksomheten til Information Research Department (IRD), en avdeling under Foreign Office som bl.a. produserte rapporter om livet bak jernteppet, til bruk i informasjonskampanjer i Vest-Europa. Også amerikanernes propaganda, både den som skjedde gjennom informasjonssentrene tilknyttet ambassadene (kjent som United States Information Service - USIS) og aktiviteter i regi av etterretningsorganisasjoner som CIA, hadde i denne tiden antikommunisme som et prioritert område. NATIS ble derfor i disse årene dels en kanal for formidling av stoff produsert av andre, dels nok en aktør som fremstilte og spredte stoff som liknet på det de største medlemslandene gjorde - og hadde gjort før 1949 (Insall, 2010; Risso, 2014).

NATIS startet riktignok tidlig med å produsere informasjonsmateriell særlig om de militære sidene ved NATO, bl.a. til bruk i militær utdanning og opplæring, og de bidro til de nevnte studiereisene for journalister og andre. Etter hvert ble det også produsert og distribuert filmer etter mønster av ECA-informasjonsarbeidet. Et tidlig eksempel er filmen «Alliance for peace» fra 1952, som var produsert for SHAPE, og betalt av amerikanske myndigheter. Den ble distribuert gjennom USIS-systemet, og hadde klare likheter med eldre filmer i det den understreket betydningen av felleskap og samarbeid. Filmen tok utgangspunkt i utbruddet av Korea-krigen, og de alliertes tiltak for å unngå kommunistiske angrep også i Europa. Den fulgte bl.a. Dwight D. Eisenhowers reise til hvert enkelt medlemsland etter at han var utnevnt som den første SACEUR, og viste glimt fra de ulike landene som nok appellerte til publikums forhåndsoppfatninger om sine allierte: Den lille havfrue i København, Leiv Eiriksson-statuen i Reykjavik, fjord og snødekte fjell i Norge, osv. I tillegg formidlet den at kommunistiske forsøk på å organisere demonstrasjoner mot Eisenhower fikk svært begrenset oppslutning, og viste frem hvordan det praktiske arbeidet $\mathrm{i}$ alliansen ble organisert. Filmen ble populær og var mye brukt. Mens film og annet materiale i begynnelsen av 1950-årene la stor vekt 
på NATO som militær allianse, opprettet for å møte trusselen fra kommunismen, ble man i NATIS gradvis mer bevisst betydningen av å vektlegge andre aspekter ved alliansesamarbeidet. Selv om det fortsatt ble produsert filmer hvis hovedformål var militær opplæring, ble også temaer som politisk og økonomisk samarbeid satt på dagsorden, og antikommunismen tonet noe ned (Risso, 2009; Danielsen, 2017).

\section{Samarbeid med norske aktører}

Både i arbeidet med å fremstille alliansen i et positivt lys, og i de antikommunistiske propagandafremstøtene, arbeidet britene, amerikanerne og (etter hvert) NATIS tett sammen med norske aktører. IRD-rapporter ble distribuert til de største avisenes utenriksredaksjoner, og pressemeldinger og annet informasjonsmateriell ble sendt ut både fra den britiske og den amerikanske ambassaden til avisredaksjoner over hele landet, og til NRK - som riktignok var relativt forsiktig med å ta inn denne typen stoff. Både IRD, USIS og andre amerikanske aktører pleide nær kontakt med miljøer og enkeltpersoner innen politikk og organisasjonsliv, og særlig arbeiderbevegelsen var en viktig målgruppe. En av de første store IRD-rapportene om forholdene i Sovjetunionen ble f.eks. oversatt til norsk og bearbeidet av Haakon Lie, og publisert i Arbeiderbladet i april 1948. Stoff fra IRD ble også brukt bl.a. i valgkampmateriell i 1953, og også amerikansk materiell ble oversatt og tilrettelagt av Lie eller andre. Noe av dette skjedde i samarbeid med den CIA-finansierte Congress for Cultural Freedom (CCF), hvor Lie var norsk kontaktperson. CCFs virksomhet var så vidt man kjenner til relativt begrenset i Norge, bl.a. fordi norske aktører på den ikke-kommunistiske venstresiden selv drev utstrakt (og effektiv) antikommunistisk agitasjon - men altså med en viss input fra allierte lands informasjonstjenester (Hannemann, 1999, s. 26; Løvhaug, 2007, s. 222ff; Bones, 2007, s. 192f; Insall, 2009).

I likhet med NATIS skjedde det også i britisk og amerikansk offentlig diplomati en delvis endring i valg av temaer og virkemidler noen år inn på 1950-tallet. Flere forskere har vektlagt betydningen av Stalins død i mars og våpenhvilen i Korea i juli 1953 for å forklare utviklingen i vestlig propaganda- og påvirkningsarbeid. Disse og andre begivenheter spilte utvilsomt en rolle. Samtidig er det viktig å merke seg at det blant dem som var ansvarlige for dette arbeidet fantes et sterkt ønske om å vri det i retning en positiv fremstilling av f.eks. USAs internasjonale rolle, vestlig samarbeid og NATO, også på et langt tidligere tidspunkt. Både britiske og amerikanske representanter advarte mot propaganda som var for åpenbar, eller for ensidig antikommunistisk, og fryktet at for banale virkemidler ville virke mot sin hensikt i møtet med et norsk publikum. De understreket dessuten betydningen av å samarbeide med norske personer og miljøer for å nå bredt ut. Nordmenn ble oppfattet som en målgruppe som var mer mottakelig for påvirkning fra sine egne enn utenfra (Insall, 2010, Danielsen, 2009, 2010).

Denne strategien var helt sentral i USIS sitt langsiktige arbeid i Norge. Et konkret, og mer avgrenset eksempel, er hvordan både briter, amerikanere og Nato-representanter 
samarbeidet med organisasjonen Folk og Forsvar de første årene etter at denne ble opprettet i 1951. Organisasjonen kom i stand som svar på Forsvarskommisjonen av 1946 sin etterlysning av en "sentralforening» som skulle bidra til psykologisk forsvarsberedskap (Sørlie \& Rønne, 2006, s. 71). Folk og Forsvar var en paraplyorganisasjon der både arbeidstaker- og arbeidsgiverforeninger, samt andre organisasjoner, kunne melde seg inn. Formålet var å spre kunnskap om og sikre tilslutning til offisiell norsk forsvars- og sikkerhetspolitikk. Foreningen var formelt uavhengig, men holdt seg tett til gjeldende politikk, og samarbeidet nært med både politikere og statstjenestemenn. Samtidig ble materiell fra bl.a. NATIS og USIS både brukt og videreformidlet. Den norske atlanterhavskomité, opprettet i 1955, hadde delvis samme formål, men stod betydelig friere til å ta selvstendige politiske initiativ. De to organisasjonene hadde på dette tidspunktet også til dels ulike målgrupper (Sørlie \& Rønne, 2006; Udgaard, 2015; Danielsen, 2017).

Folk og Forsvar formidlet informasjon til medlemsorganisasjonene, og både til og fra kontaktpersoner i pressen, blant politikere, i forvaltningen og i Forsvaret. Deres «Kontakt-bulletin» dekket sikkerhetsspørsmål i vid forstand, og var basert på varierte kilder: egne reiser, utenlandsk presse, stoff fra utenlandske myndigheter eller samarbeidende organisasjoner. Folk og Forsvar drev dessuten en pressetjeneste, arrangerte studiereiser og anbefalte deltakere til reiser i regi av NATO eller USA. De kanskje mest spektakulære virkemidlene som ble brukt for å spre kunnskap om Forsvarets utvikling (og oppbygging), og for å koble denne utviklingen til medlemskapet i NATO, var en serie forsvarsutstillinger i tidsrommet 1951-53. Den første fant sted på Akershus festning i midten av september 1951, og varte i fem dager, i og med at besøkstallene for de tre dagene som opprinnelig var planlagt langt overgikk arrangørens forventninger. Liknende utstillinger ble avholdt i Bergen, Trondheim og Tromsø i løpet av 1952, og i Harstad sommeren 1953. Målet var å gi publikum et inntrykk både av hvilken forfatning det norske Forsvaret var i, men viktigst: å vise frem hva det kunne bli til, som et resultat av samarbeid med og støtte fra NATO og enkeltallierte, og da først og fremst USA. Over 180000 besøkende fikk med seg disse utstillingene. Fra september til desember 1953 gjorde Folk og Forsvar dessuten en innsats for å spre det samme budskapet til beboere i andre deler av landet, da en såkalt «ambulerende forsvarsutstilling» ble fraktet rundt med tog. En av de ti vognene i dette toget var viet informasjon om NATO, en del av utstillingen som var delvis finansiert av USIS. Kostnadene for øvrig ble i hovedsak dekket av ekstraordinære tilskudd fra Forsvarsdepartementet, og Forsvaret stilte offiserer til rådighet som ciceroner underveis og på de totalt 37 stoppestedene (Danielsen, 2017, s. 11f).

\section{Avslutning}

Arbeidet med å påvirke den norske befolkningen i pro-atlantisk retning var, for å oppsummere, relativt variert - men også forholdsvis samordnet - både når det gjaldt aktører, tematikk og virkemidler. Selv om aspekter ved det som kjennetegnet dette påvirkningsarbeidet i slutten av 1940-årene og begynnelsen av 1950-årene også var 
synlige i de følgende tiårene, spilte spørsmålet om vestorientering versus nøytralisme etter hvert en noe annen rolle. I alle fall i utformingen av USAs offentlige diplomati ble alliansetilhørighet og sympatier med Vesten gradvis tonet ned som tema, og samtidig fremhevet som mål. I stedet for å snakke mye om NATO og forsvarssamarbeid, la man vekt på andre sider ved det moderne USA, som akademiske og kunstneriske prestasjoner. Langsomme virkemidler som kulturprogrammer, akademisk samarbeid, studentutveksling, og besøks- og utvekslingsprogrammer for etablerte og potensielle samfunnstopper ble ansett som bedre virkemidler enn entydig propaganda (Danielsen, 2009, 2014). Formålet var å sikre vestorientering, virkemiddelet å etablere og vedlikeholde positive forestillinger, dels om alliansesamarbeidet, men etter hvert først og fremst om den vestlige supermakten.

Denne utviklingen hang dels sammen med en profesjonalisering og endring av amerikansk påvirkningsarbeid generelt, men var også nært knyttet til oppfatninger om nordmenn som målgruppe. Disse oppfatningene var dels basert på personlige inntrykk, men også på opinionsundersøkelser. En av de første slike som ble gjennomført på vegne av USIS i Norge, i 1951, bekreftet at i overkant av $50 \%$ av de spurte helst skulle sett at Norge holdt seg utenfor blokkdannelsen. Samtidig viste den at det man kan kalle nøytralisme langt på vei var en ønskeposisjon: selv om respondentene ideelt sett ønsket et alliansefritt Norge, regnet de ikke nødvendigvis med at en slik posisjon ville være oppnåelig. På spørsmål om hva man trodde var mulig, snarere enn ønskelig, gikk svarene langt tydeligere i favør av vestorientering, ikke minst når det gjaldt de to supermaktenes troverdighet i internasjonale spørsmål. Undersøkelsen viste dessuten at det man kan kalle den norske eliten, i vid forstand, var mer positivt innstilte til alliansesamarbeidet enn befolkningen for øvrig, og ikke minst: at kun $19 \%$ av de spurte mente at utenrikspolitiske spørsmål var de viktigste i norsk politikk og samfunnsliv på dette tidspunktet. Ulike innenrikspolitiske spørsmål hadde altså større politisk mobiliseringskraft enn spørsmål knyttet til Norges kald krigs-posisjon (Danielsen, 2017). Påvirkningsarbeidets innretting mot å spre kunnskap og å øke bevisstheten om internasjonale spørsmål, i tillegg til å fremme vestorientering, må også forståes i lys av dette.

\section{Om forfatteren}

Helge Danielsen er førsteamanuensis ved Institutt for forsvarsstudier, Forsvarets høgskole. Han er Dr.art i historie fra $\mathrm{UiO}$, og har bl.a. forsket på forholdet mellom Norge og USA i den tidlige kalde krigen. Han har arbeidet med temaer som amerikansk public diplomacy i Norge, og USAs våpenhjelp til Norge i 1950- og 1960-årene.

\section{Litteraturliste:}

Alstad, B. (1993). Norske meninger 1946-1993, 1. Norge og verden. Oslo: Sigma.

Bones, S. (2007). I oppdemmingspolitikkens grenseland. Nord-Norge i den kalde krigen 1947-70. (Avhandling levert for graden Doctor Artium). Universitetet i Tromsø. 


\title{
Helge Danielsen
}

Danielsen, H. (2009). Making friends at court: Slow and indirect media in US public diplomacy in Norway, 1950-1965, Contemporary European History 18 (2), s. 179-198.

Danielsen, H. (2010). Mediating public diplomacy: Local conditions and U.S. public diplomacy in Norway in the 1950s. I K. A. Osgood \& B. C. Etheridge (Red.), The United States and public diplomacy. New directions in cultural and international history (s. 285-324). Leiden: Brill Academic Publishers.

Danielsen, H. (2015). American culture as 'high culture': U.S. cultural diplomacy in Norway, 1950-65. I V. Ingimundarson \& R. Magnúsdottir (Red.), Nordic Cold War cultures. Ideological promotion, public reception, and East-West interactions (s. 17-42). Helsinki: Aleksanteri Cold War Series 2.

Danielsen, H. (2017). A military ERP? Military assistance and US public diplomacy in Norway in the early 1950s. Fournal of Transatlantic Studies 15 (4), s. 313-330.

Danielsen, H. \& Pharo, H. (2009). Reception and representation of the Marshall Plan in Norway. I G. Bischof \& D. Steifel (Red.), Images of the Marshall Plan in Europe. Films, photographs, exhibits, posters (s. 87-106). Innsbruck: StudienVerlag.

Ellwood, D.W. (2012). The shock of America. Europe and the challenge of the century. Oxford: Oxford University Press.

Fritsche, M. (2018) The American Marshall Plan film campaign and the Europeans: A captivated audience? London: Bloomsbury Academic.

Hannemann, M. (1999). Kalter Kulturkrieg in Norwegen? Zum Wirken des 'Kongress für kulturelle Freiheit' in Skandinavien. NORDEUROPAforum, Zeitschrift für Politik, Wirtschaft und Kultur 2 (2), s 15-41.

Insall, T. (2010). Haakon Lie, Denis Healy and the making of an Anglo Norwegian special relationship 1945-1951. Oslo: Unipub.

Liland, F. (1992). De som elsket Amerika: Kollektive forestillinger om Amerika i Norge, 1945-1949. (Hovedoppgave i historie). Universitetet i Oslo.

Løvhaug, J. (2007). Politikk som idékamp. Et intellektuelt gruppeportrett av Minervakretsen 1957-1972. Oslo: Pax.

Opinion for Folk og Forsvar. (2018). Meningsmålinger om Forsvaret og internasjonalt samarbeid. Hentet fra https:/www.folkogforsvar.no/wp-content/uploads/2018/09/Meningsmålinger-om-Forsvaret-og-internasjonalt-samarbeid-august-2018.pdf

Pharo, H. (1976). Bridge-building and reconstruction: Norway faces the Marshall Plan. Scandinavian fournal of History, 1 (1-2), s. 125-153.

Risso, L. (2009). Don't mention the Soviets! An overview of the short films produced by the NATO Information Service between 1949 and 1969. Cold War History, 9 (4), s. 501-512.

Risso, L. (2011). Propaganda on wheels: the NATO travelling exhibitions in the 1950s and 1960s. Cold War History, 11 (1), s. 9-25.

Risso, L. (2014). Propaganda and intelligence in the Cold War. The NATO information service. London: Routledge.

Sverdrup, J. (1996). Inn i storpolitikken 1940-1949. Norsk utenrikspolitikks historie, Bind 4. Oslo: Universitetsforlaget.

Sørlie, S. og Rønne H. K. (2006). Hele folket i forsvar. Totalforsvaret $i$ Norge frem til 1970. Oslo: Unipub.

Tamnes, R. (1997). Oljealder 1965-1995. Norsk utenrikspolitikks historie, Bind 6. Oslo: Universitetsforlaget.

Udgaard, N. M. (2015). En arena for norsk sikkerhetsdebatt i 60 år. Oslo: Den norske atlanterhavskomité.

\begin{abstract}
English
Abstract in English: Since the end of the 1960s, there has been a high degree of public support for Norwegian membership in NATO. In the late 1940s and well into the 1950s, however, several public opinion surveys showed that approximately $50 \%$ of the population ideally would have preferred Norwegian non-alignment. This article analyses how (soon to be) allies, as well as NATOs own information agency sought to influence Norwegian public opinion in the years just before and after 1949, often in cooperation with Norwegian individuals or organisations. These efforts aimed at increasing public attention to and knowledge of the Alliance, and sought to secure public support for the Norwegian Government's Atlantic policies.
\end{abstract}

Keywords: public diplomacy $\cdot$ public opinion $\cdot$ neutralism $\cdot$ NATO 